\title{
Prediction of aggression on a locked psychiatric admissions award.
}

Citation for published version (APA):

Nijman, H., Merckelbach, H. L. G. J., Evers, C., Palmstierna, T., \& a Campo, J. M. L. G. (2002). Prediction of aggression on a locked psychiatric admissions award. Acta Psychiatrica Scandinavica, 105(5), 390395. https://doi.org/10.1034/j.1600-0447.2002.0o426.x

Document status and date:

Published: 01/01/2002

DOI:

10.1034/j.1600-0447.2002.00426.x

Document Version:

Publisher's PDF, also known as Version of record

\section{Please check the document version of this publication:}

- A submitted manuscript is the version of the article upon submission and before peer-review. There can be important differences between the submitted version and the official published version of record.

People interested in the research are advised to contact the author for the final version of the publication, or visit the DOI to the publisher's website.

- The final author version and the galley proof are versions of the publication after peer review.

- The final published version features the final layout of the paper including the volume, issue and page numbers.

Link to publication

\footnotetext{
General rights rights.

- You may freely distribute the URL identifying the publication in the public portal. please follow below link for the End User Agreement:

www.umlib.nl/taverne-license

Take down policy

If you believe that this document breaches copyright please contact us at:

repository@maastrichtuniversity.nl

providing details and we will investigate your claim.
}

Copyright and moral rights for the publications made accessible in the public portal are retained by the authors and/or other copyright owners and it is a condition of accessing publications that users recognise and abide by the legal requirements associated with these

- Users may download and print one copy of any publication from the public portal for the purpose of private study or research.

- You may not further distribute the material or use it for any profit-making activity or commercial gain

If the publication is distributed under the terms of Article $25 \mathrm{fa}$ of the Dutch Copyright Act, indicated by the "Taverne" license above, 


\section{Prediction of aggression on a locked psychiatric admissions ward}

\author{
Nijman H, Merckelbach H, Evers C, Palmstierna T, à Campo J. \\ Prediction of aggression on a locked psychiatric admissions ward. \\ Acta Psychiatr Scand 2002: 105: 390-395. (C) Blackwell Munksgaard \\ 2002.
}

Objective: The present study evaluates the accuracy of clinical and archival predictors of patients' aggressive behaviour on a locked admissions ward.

Method: Over a 9-month period, staff members estimated the likelihood that patients would become aggressive during their stay in the ward. These unaided clinical assessments were obtained with Visual Analogue Scales (VASs) administered before the end of the first full day of admission. Archival predictions were based on demographic variables (e.g. gender, number of previous admissions, diagnosis) derived from patients' admission forms. Aggressive behaviour was recorded with the Staff Observation Aggression Scale-Revised (SOAS-R).

Results: Clinical predictions of aggression were found to be moderately accurate. On the basis of clinical estimates, $75 \%$ of the patients were correctly classified as becoming aggressive or not. Conclusion: Although a body of evidence indicates that unaided clinical prediction of violent recidivism after hospital discharge does not perform well, it may be quite accurate in estimating short-term aggression risks during acute psychiatric admission.

\section{H. Nijman ${ }^{1}$, H. Merckelbach ${ }^{2}$, C. Evers ${ }^{3}$, T. Palmstierna ${ }^{4}$, J. à Campo ${ }^{5}$}

'Forensic Psychiatric Hospital the Kijvelanden, Poortugaal, the Netherlands and Faculty of Law. Maastricht University, Maastricht, the Netherlands ${ }^{2}$ Department of Experimental Psychology. Faculty of Law, Maastricht University, Maastricht, the Netherlands, ${ }^{3}$ Department of Social Psychology. University of Amsterdam, Amsterdam, the Netherlands. ${ }^{4}$ Section for Dependency Disorders, St Göran Hospital and Department of Clinical Neurosciences, Karalinska Institute, Stockholm, Sweden and ${ }^{5}$ Inpatient Facility of Mondriaan Zorggroep, Heerlen, the Netherlands

Key words: aggression; violence; assaultiveness: prediction

Henk Nijman, Forensic Psychiatric Haspital de Kjivelanden, PO Box 900, 3160 AC Rhoon, the Netherlands E-mail: hennij@kijvelanden.n|

Accepted for publication 12 November, 200

\section{Introduction}

In-patient aggression threatens the safety and well-being of both staff members and patients (1). Nursing staff in particular is at risk of being assaulted (1-6). Apart from its physical and psychological consequences, in-patient aggression has considerable financial implications. For example, Carmel and Hunter (7) reported an annual total of 134 serious injuries in a 973 bed forensic psychiatric hospital. The average costs per injury were conservatively estimated to be $\$ 5719$, making the total annual loss \$766 290 .

Given its far-reaching consequences, aggression prevention in psychiatric in-patient facilities should have a high priority. For effective prevention, although, it is essential that clinicians are able to predict violent behaviour of psychiatric patients with a sufficient degree of accuracy (8).

There has been some debate about the merits of clinical vs. actuarial prediction of aggression. In clinical judgment, information about the probability and risk of violence is processed inside the head of the decision-maker, whereas in actuarial (or statistical) methods, the human judge is eliminated. Conclusions are solely drawn on the basis of established empirical knowledge $(9,10)$. In their review, Harris and Rice (8) concluded that 'actuarial methods are more accurate in predicting risk than unaided clinical judgment' (p. 1168; see also 11). In actuarial predictions, a history of earlier violence is regarded as one of the best predictors of aggression (e.g. 3, 8, 11, 12). Harris and Rice ( 8 ) suggested that, apart from earlier violence, poor social adjustment, substance abuse, antisocial personality disorder, and psychopathy (see also 13) are closely connected to a heightened risk of violence.

Although clinical judgments have had a bad press over the past years (e.g. 9), not all authors agree that this type of judgment is necessarily of poor quality (14-18). Although a recent metaanalysis (18) confirms the overall superiority of actuarial prediction in general, it also points out that in about half of the studies, both types of method reached comparable levels of accuracy. 
Furthermore, in 6-16\% of the studies, clinical prediction outperformed actuarial methods.

It is worthy of note that aggression prediction studies have mainly focused on predicting criminal recidivism or acts of violence committed by psychiatric patients after their release from hospitals (see for recent examples 11, 19-21). On a related note, most of these studies relied on archival means (e.g. file reviews) to predict follow-up violence. Findings from Mulvey and Lidz (22), however, indicate that to some extent, clinicians can predict which circumstances and conditions will play a role in re-offending after hospital discharge. It is also important to stress that only a handful of studies addressed prediction of violent behaviour during the first few weeks of psychiatric hospitalization (14-16,23). Meanwhile, manifestations of aggressive behaviour are highly prevalent during this phase (24).

Results of studies focusing on the prediction of in-patient aggression suggest that statistical predictors may be of limited value in samples of acutely admitted in-patients (23) and that with such samples, short-term clinical prediction is reasonably accurate (14-16). A case in point is the work of McNiel and Binder $(14,15)$ who demonstrated that staff members are able to predict aggressive behaviour above chance of patients on a psychiatric admission ward. Recently, Hoptman et al. (16) investigated the validity of clinical estimates of assaultive behaviour occurring during the first 3 months of admission to a forensic psychiatric hospital. In line with the $\mathrm{McNiel}$ and Binder results $(14,15)$, clinical estimates performed above chance. Seventy-one percentage of the patients were correctly classified as either becoming assaultive or not (sensitivity: $54 \%$ and specificity: 79\%).

The current study examined the predictive power of clinical assessments in a way that resembles the procedure used by McNiel and Binder (15). However, in our study, the outcome measure i.e. aggressive behaviour) was not exclusively lefined in terms of a dichotomous present-absent variable, but also specified in terms of severity and requency of the behaviour. This is important secause violent behaviour varies considerably in requency and severity per patient. Therefore, rediction methods should be studied '(..) not mly on whether they can identify patients who are iolent but also on whether the methods can dentify patients involved in frequent or severe 'ggression' (11, p. 603).

In the current study, aggression was recorded vith a psychometrically sound instrument (i.e. the itaff Observation Aggression Scale-Revised or ;OAS-R in short), which was specifically developed for measuring both frequency and severity of aggression $(25,26)$.

\section{Material and methods}

The study was conducted on a 20-bed locked admission ward of psychiatric hospital Welterhof, the Netherlands. Patients admitted to this ward are adults with severe psychiatric disorders (e.g. schizophrenia or mania) who need a locked environment to protect them or others from harm. Crisis intervention and diagnostic evaluation are the main goals on this ward. The admission duration on this ward is relatively short, with a median length of stay of 28.5 days. If prolonged hospitalization is required patients usually are referred to other wards of the same hospital.

\section{Clinical estimates of aggression}

For each admission during the study-period (i.e. 20 November 1997-21 August 1998), qualified nursing staff members were asked to provide risk assessments of the probability that the patient would explicitly exhibit aggressive behaviour during his or her stay at the locked ward. Staff members had received no formal training on prediction of aggression and no aggression risk assessment instruments were used on the ward under study. The unaided clinical estimates were provided on $100 \mathrm{~mm}$ horizontal Visual Analogue Scales (VASs). In general, VASs are regarded as suitable tools for quantifying rather subjective phenomena (see 27).

For the prediction of physical aggression, staff members used a VAS with anchor points ranging from 'this patient will definitely not become physically aggressive' (left side or $0 \%$ end) to 'this patient will definitely become physically aggressive' (right side or $100 \%$ end). To assess the likelihood of verbal aggression, staff members used a VAS anchored by: 'this patient definitely will not become verbally aggressive' (left; $0 \%$ ) and 'this patient definitely will become verbally aggressive' (right; $100 \%$ ). To be included in the analyses, VAS ratings had to be malde before the end of the first full day of admission and no aggression should have been displayed by the patient before VASs were scored.

In total, 98 admissions took place during the study period (i.e. 20 November 1997-21 August 1998). For 89 of these admissions (91\%), risk assessments (VASs) were completed at intake or during the first day of admission and before the patient displayed any kind of aggression. The remaining nine patient records were excluded from 


\section{Nijman et al.}

the analyses. The 89 VASs were completed by 20 different staff members. The average age at admission of the 89 assessed patients was 36.0 years $(\mathrm{SD}=12.1)$ and more than half of the patients $(61 \%)$ were men.

\section{Archival predictors of aggression}

Apart from the VASs, a number of global predictors were derived from the admission forms. In order to assess their usefulness as genuine predictors, only those variables that are directly available at admission should be included (see 1I). Thus, diagnosis at admission rather than the more reliable discharge diagnosis was used. For this reason, the current study relied on a crude diagnostic categorization in psychotic disorders (i.e. schizophrenia, schizofreniform, schizoaffective, delusional, and psychotic disorders not otherwise specified) vs. other diagnoses to assess the predictive validity of type of psychopathology. In addition, information about the following variables were included: legal status at admission, age, gender, number of previous admissions in our hospital (because this is the only information that is directly available at admission), and whether the patient had a history of involuntary hospitalizations in our hospital.

On the basis of previous research (1), we anticipated that young age, high re-admission rate, and involuntary hospitalization (either at the index admission or at an earlier admission) would be reliable predictors of aggression. Note that under Dutch law, forced hospitalization is only allowed in cases where the patient's behaviour constitutes a direct and clear danger to others or the patient. In practice, this means that involuntary admissions are nearly always preceded by some form of aggressive or self-harming behaviour.

\section{Assessment of actual aggression}

Aggression was monitored with the revised version of $\operatorname{SOAS}(25,26,28)$ by the multidisciplinary ward team. The SOAS is a widely used instrument for measuring both nature and severity of aggressive behaviour (e.g. 1, 26, 28, 29). Initial testing of the SOAS suggested satisfactory reliability $(1,28)$, Palmstierna and Wistedt (28) reported an intriclass correlation between total SOAS scores of 0.96. On the basis of this and other findings, Shah et al. (3) classified the SOAS in 1991 to be an instrument "of particular interest (..) with evidence of good reliability and validity' (p. 307).

More recent studies have addressed the validity of SOAS severity ratings $(25,29-31)$. For example,
Shah and colleagues $(30,31)$ cross-validated SOAS severity scores with those of the Rating Scale for Aggressive Behaviour in the Elderly (RAGE; 32). Correlations between RAGE and SOAS severity scores were found to be quite high in both studies $(r \geq 0.79)$. SOAS-severity scores were also found to be associated with severity ratings of other wellknown aggression scales (i.e. the Modified Overt Aggression Scale or MOAS in short; the Social Dysfunction and Aggression Scale or SDAS, and the Violence Scale or VS; see 29).

Using a different approach, Nijman et al. (25) correlated SOAS severity ratings with severity judgments made by staff members. Clinical severity ratings correlated moderately $(r=0.38)$, but significantly with the original SOAS severity ratings as proposed by Palmstierna and Wistedt in 1987 (28). In order to approach clinical judgments of staff more closely, Nijman et al. (25) developed a revised version severity scoring system for the SOAS. Severity scores of this new version of the SOAS, which was termed SOAS-R, correlated more strongly $(r=0.60)$ with clinical estimates of aggression severity provided by staff members. The SOAS-R defines aggression as 'any verbal, nonverbal, or physical behaviour that is threatening (to self, others, or property), or physical behaviour that actually does harm (to self, others, or property)' (in 33).

In the current study, the SOAS-R was completed by staff members each time they witnessed aggressive behaviour. In order to get reliable information about aggressiveness for every included patient, SOAS-R data collection was prolonged for six additional weeks after the final clinical VAS ratings had been provided (i.e. till 2 October 1998).

It was only after the data-collection phase that aggressive incidents were categorized by the researchers in terms of their severity. Severity of aggressive incidents was rated following the SOAS$\mathrm{R}$ severity scoring system (25). With this system, severity of outwardly directed aggressive incidents varies from 0 (least severe form of aggression) to 22 (most severe form of aggression).

\section{Statistical tests}

With univariate tests ( $t$-tests and chi-squared lests), we examined whether clinical VAS ratings, diagnostic status, age, sex, re-admission rate, and involuntary hospitalization were associated with aggressive behaviour during the index admission. Separate analyses were conducted for patients who engaged in physical aggression. With correlational analyses (Speaman's $\rho$ ), we examined to what extent clinical VAS ratings could predict the 
number and severity of aggressive incidents. All analyses were uniformly conducted two-tailed, and $\alpha$ was set on 0.05 . The predictive power (i.e. sensitivity and specificity) of significant predictors was evaluated further by means of multiple logistic regression analyses.

\section{Results}

Aggressive behaviour

During 31 of the 89 admissions (35\%), patients became aggressive (as measured with the SOAS-R). Aggression was likely to occur early during patients' hospitalization. The median number of days until the first aggressive outburst was 5. In total, 195 aggressive incidents could be attributed to the aggressive subsample of 31 patients (mean $=6.3$ incidents per aggressive patient). The number of aggressive episodes per patient varied considerably, from 1 to 56 incidents. The average severity - in terms of the mean SOAS-R score (19) for the most severe incident of each patient -. - was $12.2(\mathrm{SD}=4.8$, range $2-19)$.

About half of the incidents (i.e. 102 of the 195 incidents or $52 \%$ ) involved physical behaviour (usually in addition to verbal aggression). Of the 31 aggressive patients, 23 were involved in physical aggression of some kind (range: 1-28 physical aggressive incidents per patient).

Clinical estimates of aggression

Staff members providing VAS ratings had, on average, 9.9 years of working experience with psychiatric patients $(S D=7.7)$. Table 1 , shows mean VAS scores pertaining to patients who ultimately did and those who did not become aggressive. VAS ratings were significantly raised for patients who displayed any form of aggressive behaviour during their admission period.

Tabie 1. Mean clinical Visual Analogue Scale (VAS) ratings of staff for aggressive and non-aggressive patients

\begin{tabular}{lccc}
\hline & $\begin{array}{c}\text { Aggressive } \\
\text { patients } \\
(n=31)\end{array}$ & $\begin{array}{c}\text { Non-aggressive } \\
\text { patients } \\
(n=58)\end{array}$ & $\begin{array}{c}\text { Effect size } \\
\text { (Cohen's d }\end{array}$ \\
\hline $\begin{array}{l}\text { VAS 1 } \\
\text { (subjective probability of } \\
\text { physical aggression)t }\end{array}$ & $51.4(29.0)$ & $21.6(20.4)$ & 1.2 \\
$\begin{array}{l}\text { VAS 2 } \\
\text { (subjective probability of } \\
\text { verbal aggressionl+ }\end{array}$ & $637(29.3)$ & $37.2(27.9)$ & 0.90 \\
\hline
\end{tabular}

"Values are given as mean VAS (SO).

$+t(87)=5.6, P<0.05$

$t(87)=4.2, P<0.05$
Separate analyses of the scores of the 23 physically aggressive patients - compared with the remaining 66 patients who had not been involved in physical aggressive behaviour - also yielded significant differences [i.e. for VAS $1(t(87)=4.0$, $P<0.05)$ and for VAS $2(t(87)=3.0, P<0.05)]$.

Clinical VAS predictions were also found to correlate with severity (absolute SOAS-R severity score of the most severe incident for each patient) and frequency of aggressive incidents per patient. More specifically, the (Spearman's $\rho$ ) correlations between VAS 1 and VAS 2 on one hand, and SOAS-R aggression severity on the other were 0.51 and 0.44 , respectively $(n=88 ; 1$ missing value; both $P$ values $<0.05$, two-tailed). VAS 1 and VAS 2 were also significantly associated with the number of incidents per patient $(0.50$ and 0.43 , respectively; $n=89$; both $P<$ values 0.05 , twotailed).

\section{Statistical predictors of aggression}

Table 2 summarizes the results of univariate tests of associations between archival predictors and patients' violence. Results indicate that a history of involuntary admission was a significant predictor of aggressive behaviour during the index hospitalization. Note, however, that the other actuarial variables were not connected to aggression (i.e. $P$-values were all above 0.05 , two-tailed).

Separate analyses on the subsample of the 23 physically aggressive patients yielded highly similar results. That is, only earlier involuntary hospitalization tended to be related with physical aggression during the index admission, but the connection did not attain significance anymore $\left[\chi^{2}(1)=3.2, P=0.08\right]$.

\section{Logistic regression analyses}

To evaluate to what extent aggressive behaviour during hospitalization on an acute locked

Table 2. The relationships between archival predictors (i.e. age, gender, re-admission rate, legal status, and diagnosis) and aggressive behaviour

\begin{tabular}{lll}
\hline & $\begin{array}{c}\text { Aggressive } \\
\text { patients }(n=31)\end{array}$ & $\begin{array}{c}\text { Non-aggressive } \\
\text { patients }(n=58)\end{array}$ \\
\hline Age lyears) & $37.4(\mathrm{SD}=15.2)$ & $35.2(\mathrm{SD}=10.0)$ \\
Gender & $19 \mathrm{Men}(61 \%)$ & $35 \mathrm{Men}(60 \%)$ \\
Re-adrission rate & 6.5 Priór admissions & 4.6 Prior admissions \\
& $(\mathrm{SO}=6.9)$ & $(\mathrm{SD}=4.9)$ \\
Legal status at index admission & 17 Involuntary $(55 \%)$ & 21 Involuntary $(36 \%)$ \\
History of involuntary admissions* & 19 Positive $(61 \%)$ & 21 Positive $(36 \%)$ \\
Psychotic disorder & $21(68 \%)$ & $29(50 \%)$ \\
\hline
\end{tabular}

$* 2(1)=5.1, p<0.05$ 
psychiatric admission ward can be predicted, variables that were found to be significant in the statistical tests reported above (i.e. VAS 1 and 2, and earlier involuntary hospitalization) were entered in a forward stepwise logistic regression analysis, with aggression status (i.e. 31 aggressive patients vs. 58 non-aggressive patients) as the dependent variable. In the first step, VAS 1 scores were entered. On the basis of this clinical estimate, 67 of 89 patients $(75 \%)$ could be correctly classified as becoming aggressive or not. The sensitivity of the model was $55 \%$, whereas the specificity was $86 \%$.

To illustrate the clinical implications of these results; a patient with a score of $85 \mathrm{~mm}$ on VAS 1 has - according to the regression model - a probability of $83 \%$ of displaying aggressive behaviour in the near future. In case of the maximum estimated risk (i.e. $100 \mathrm{~mm}$ on VAS 1), the risk of becoming aggressive increases to $91 \%$ in the model.

After inclusion of VAS 1, the other variables (i.e. VAS 2 and earlier involuntary hospitalization) could not make an additional significant contribution to the model. Forced entry of the two remaining variables, indeed, demonstrated that inclusion of these two additional predictors hardly increased the accuracy of the model (i.e. overall accuracy $76 \%$; sensitivity: $58 \%$; specificity: $86 \%$ ).

Interestingly, even when all archival variables listed in Table 3 [i.e. being psychotic or not, age, sex, re-admission rate, and information about (earlier) involuntary hospitalizations] were forced in the equation on step 1, VAS 1 still contributed significantly to the accuracy of the model in step 2 .

\section{Discussion}

The current study examined the accuracy of unaided clinical prediction of aggression and that of easily accessible archival variables on a locked psychiatric admission ward. In contrast to the prevailing notion that unaided clinical prediction of aggression is poor, it was found that staff members performed above chance in predicting aggression during acute hospitalization (see for similar conclusions 14,15).

A number of limitations of the current study deserve comment. To begin with, our study is silent about how staff members succeed in predicting aggression above chance. As patients in the current study had a relatively high re-admission rate in the same hospital, earlier experiences with, and knowledge about re-admitted patients, may have contributed to the accuracy of clinical prediction of aggression. Also, as staff members will have taken other variables into account, than solely the presented crude archival ones, the current stud. cannot be regarded as a direct and fair comparison between clinical and archival prediction.

Secondly, one could argue that the relatively good performance of clinical prediction found in the current study was the result of a self-fulfilling prophecy. That is, staff members who believe that a particular patient will become aggressive may be more willing to record minor aggressive acts of that patient. Although this possibility cannot be ruled out, it should be noted that separate analyses of VAS-scores of patients who displayed more severe (and possibly less subjective) manifestations of aggression (i.e. physical aggression) did also yield significant results.

Thirdly, as mentioned above, the archival predictors included in the current study were crude. In everyday clinical practice, however, detailed empirical knowledge of subtle actuarial parameters of recently admitted patients is often also lacking. It may well be the case that archival predictors specifically are accurate in predicting violent or criminal recidivism after discharge (e.g. 21), precisely because the admission period allows for detailed and objective information about the patient to be obtained through observations, screening instruments, and collateral sources. Indeed, most actuarial prediction methods, rely on rather sophisticated, yet time-consuming tools $(13,19,20)$. Such assessments are typically not available during the first admission days. Even so, during these early days important decisions have to be made.

Although its merits should not be exaggerated, our results suggest that clinical prediction may have some value on locked acute admission wards. Perhaps the short-term accuracy of such predictions has to do with staff members being able to take into account fluctuating environmental variables. Especially on locked wards, negative environmental cues (e.g. ward crowding, understaffing: 34) may be involved in eliciting aggression, as patients have no possibilities to escape them. In contrast, actuarial prediction capitalizes on patient variables at the expense of fast fluctuating ward or staff variables. Further, as locked wards staff form the most likely target of such aggression $(1-6)$, their sensitivity to and knowledge of aggression predictors may be relatively good.

If easily obtainable clinical estimates are, indeed, accurate in the sense that they predict short-term aggressive behaviour on locked psychiatric admission wards above chance, the question arises whether they can be used in some way to prevent dangerous situations. If nothing else, a simple VAS 
measure can be used to put aggression prevention on the agenda of ward team meetings, even before actual violence occurs. In everyday clinical practice, aggression prevention all too often becomes a topic after severe incidents have already occurred.

\section{References}

1. Nisman HLI, Allertz WWF, Merckelbaci H, A Campo J, Ravella D. Aggressive behaviour on an acute psychiatric admissions ward. Eur J Psychiatry 1997;11:106-114.

2. Drinkwater J, Gudjonsson GH. The nature of violence in psychiatric hospitals. In: Howells, K, Hol.LIN, RC, eds. Clinical approaches to violence. New York: John Wiley \& Sons, 1989:387-407.

3. Shat A, Fineberg N, James D. Violence among psychiatric inpatients. Acta Psychiatr Scand 1991;84:305-309.

4. Tamm E, Engelsmann F, Fugere R. Patterns of violent incidents by patients on a general hospital psychiatric facility. Psychiatr Serv 1996;47:86-88.

5. Carmel H. Hunter M. Staff injuries from inpatient violence. Hosp Commun Psychiatry 1989;40:41-46.

6. Chueng P, Schweitzer I, Tuckwell V, Crowley KC. A prospective study of aggression among psychiatric patients in rehabilitation wards. Aus NZ J Psychiatry 1996;30:257-262.

7. Hunter M, Carmel $H$. The cost of staff injuries from inpatient violence. Hosp Commun Psychiatry 1992;43:586588

8. HARris GT, Rice ME. Risk appraisal and management of violent behavior. Psychiatr Serv 1997;48:1168-1176.

9. Dawes RM, Faust D, Meehl PE. Clinical versus actuarial judgment. Science 1989;243:1668-1673.

10. Wedding D, Faust D. Clinical judgment and decision making in neuropsychology. Arch Clin Neuropsychol 1989:4:223-265.

11. Gardner W, Lidz CW, Mulvey EP, Shaw EC. Clinical versus actuarial predictions of violence in patients with mental illnesses. J Consult Clin Psychol 1996; 64:602-609.

12. TardifF $K$. The current state of psychiatry in the treatment of violent patients. Arch Gen Psychiatry 1992;49:164-116.

13. HART SD, HARE RD. Psychopathy and risk assessment. Current Opinion Psychiatry 1996;9:380-383.

14. MCNIEL DE, BINDER RL. Clinical assessment of the risk of violence among psychiatric inpatients. Am J Psychiatry 1991:148:1317-1321.

15. MCNIEL DE, BINDER RL. Correlates of accuracy in the assessment of psychiatric inpatients' risk of violence. Am J Psychiatry 1995;152:901-906

16. Hoptman MJ, Yates KF, PAtalingugg MB, Wack RC, Convit A. Clinical prediction of assaultive behavior among male psychiatric patients at a maximum-security forensic facility. Psychiatr Serv 1999;50:1461-1466.

17. LiJz CW, Mulvey EP, Gardner W. The accuracy of predictions of violence to others. JAMA 1993;269:1007-1011.

18. Grove WM, Zald DH, Lebow BS, Snitz BE, Nelson C. Clinical versus mechanical prediction: a meta-analysis. Psychol Assessment 2000;12:19-30.

19. Monahan J. Steadman HJ, Appel.baum PS el al. Developing a clinically useful actuarial tool for assessing violence risk. Br J Psychiatry 2000;176:312-319.

20. Douglas KS, Ogloff JRP, Grant I, Nicholls TL. Assessing risk for violence among psychiatric patients: the HCR-20 violence risk assessment scheme and the psychopathy checklist: screening version. J Consult Clin Psychol 1999;67:917-930.

21. KJelsberc E, Dahl AA. A long-term follow-up study of adolescent psychiatric in-patients. Part II. Predictors of delinquency. Acta Psychiatr Scand 1999;99:237-242.

22. Mutvey EP, LID $Z$ CW. Clinical prediction of violence as a conditional judgment. Soc Psychiatry Psychiatr Epidemiol 1998:33:107-113.

23. Palmistierna T, Wistedt B. Risk factors for aggressive behaviour are of limited value in predicting the violent behaviour of acute involuntarily admitted patients. Acta Psychiatr Scand 1989;81:152-155.

24. Davis $S$. Violence by psychiatric inpatients: a review. Hosp Commun Psychiatry 1991:42:585-590.

25. Numan HLi. Muris P. Merckelbacil HLGJ et al. The Staff Observation Aggression Scale-Revised (SOAS-R). Aggr Behav 1999;25:197-209.

26. Palmstierna T, Nijman Hli, Wistedt B, Merckelbach HLGJ. Revision of the Staff Observation Aggression Scale (SOAS): comment on Hallsteinsen et al. Acta Psychiatr Scand 1999;100:80-81.

27. GifT AG. Visual Analogue Scales. Measurement of subjective phenomena. Nurs Res 1989;38:286-288.

28. PAlmstierna T, Wistedt B. Staff" observation aggression scale. Presentation and evaluation. Acta Psychiatr Scand 1987;76:657-663.

29. Steinert T, Wölfle M, Glbhardt RP. Measurement of violence during in-patient treatment and association with psychopathology. Acta Psychiatr Scand 2000:102:107-112.

30. Shah A, Chiu E, Ames D. The relationship between two scales measuring aggressive behavior among elderly nursing home residents. Int J Geriatr Psychiatry 1997;12:628-631.

31. SHAн A. DE T. The relationship belween two scales measuring aggressive behavior among continuing-care psychogeriatric inpatients. Int Psychogeriatr 1997:9:471-477.

32. PATEL V, HOPE RA. A rating scale for aggressive behavior in the elderly. Psychol Med 1992;22:211-221.

33. Morrison EF. Violent psychiatric inpatients in a public hospital. Schol Inq Nurs Pract Int J 1990:4:65-82.

34. Nijman HLI, a Campo JMLG, Ravelli DP. Mercki:L BACH HLGJ. A tentative model of aggression on inpatient psychiatric wards, Psychiatr Serv 1999;50:832-834. 
measure can be used to put aggression prevention on the agenda of ward team meetings, even before actual violence occurs. In everyday clinical practice, aggression prevention all too often becomes a topic after severe incidents have already occurred.

\section{References}

1. Nisman HLI, Allertz WWF, Merckelbach $H$, Á CAmpo J, Ravell D. Aggressive behaviour on an acute psychiatric admissions ward. Eur J Psychiatry 1997;11:106-114.

2. Drinkwater J, Gudjonsson GH. The nature of violence in psychiatric hospitals. In: Howells, K, Hollin, RC, eds. Clinical approaches to violence. New York: John Wiley \& Sons, 1989:387-407.

3. Shah A, Fineberg N, James D. Violence among psychiatric inpatients. Acta Psychiatr Scand 1991;84:305-309.

4. Tamm E, Engelsmann F, Fugere R. Patterns of violent incidents by patients on a general hospital psychiatric facility. Psychiatr Serv 1996;47:86-88.

5. Carmel H. Hunter M. Staff injuries from inpatient violence. Hosp Commun Psychiatry 1989;40:41-46.

6. Chueng P, Schweitzer I, Tuckwell V, Crowley KC. A prospective study of aggression among psychiatric pationts in rehabilitation wards. Aus NZ J Psychiatry 1996;30:257-262.

7. Hunter M, Carmel $H$. The cost of staff injuries from inpatient violence. Hosp Commun Psychiatry 1992;43:586588.

8. HARris GT, Rice ME. Risk appraisal and management of violent behavior. Psychiatr Serv 1997;48:1168-1176.

9. Dawes RM, Faust D, Meehl PE. Clinical versus actuarial judgment. Science 1989:243:1668-1673.

10. Wedding D, Faust D, Clinical judgment and decision making in neuropsychology. Arch Clin Neuropsychol 1989:4:223-265.

11. Gardner W, Lidz CW, Mulvey EP, Shaw EC. Clinical versus actuarial predictions of violence in patients with mental illnesses. J Consult Clin Psychol 1996; 64:602-609.

12. TARDIFF $K$. The current state of psychiatry in the treatment of violent patients. Arch Gen Psychiatry 1992;49:164-116.

13. Hart SD. HAre RD. Psychopathy and risk assessment. Current Opinion Psychiatry 1996;9:380-383.

14. MCNIEL DE. BINDER RL. Clinical assessment of the risk of violence among psychiatric inpatients. Am J Psychiatry 1991;148:1317-1321.

15. MCNIEL. DE, BINDER RL. Correlates of accuracy in the assessment of psychiatric inpatients' risk of violence. Am J Psychiatry 1995;152:901-906.

16. Hoptman mJ, Yates KF, Patalinguug MB, Wack RC, Convit A. Clinical prediction of assaultive behavior among male psychiatric patients at a maximum-security forensic facility. Psychiatr Serv 1999;50:1461-1466.

17. Limz CW, Mulvey EP, Gardner W. The accuracy of predictions of violence to others. JAMA 1993:269:1007-1011.

18. Grove WM, ZnLd DH, Lebow BS, Snitz BE, Nelson C. Clinical versus mechanical prediction: a meta-analysis. Psychol Assessment 2000;12:19-30.

19. Monahan J, Steadman HJ, Appel.baum PS el al. Developing a clinically useful actuarial tool for assessing violence risk. Br J Psychiatry 2000;176:312-319.

20. Douglas KS, Ogloff JRP, Grant I, Nicholls TL. Assessing risk for violence among psychiatric patients: the HCR-20 violence risk assessment scheme and the psychopathy checklist: screening version. J Consult Clin Psychol 1999;67:917-930.

21. KJelsberg E, Dahl AA. A long-term follow-up study of adolescent psychiatric in-patients. Part Il. Predictors of delinquency. Acta Psychiatr Scand 1999:99:237-242.

22. Mulviry EP, Lidz CW. Clinical prediction of violence as at conditional judgment. Soc Psychiatry Psychiatr Epidemiol 1998:33:107-113.

23. Palmistierna T, Wistedt B. Risk factors for aggressive behaviour are of limited value in predicting the violent behaviour of acute involuntarily admitted patients. Acta Psychiatr Scand 1989;81:152-155.

24. Davis $S$. Violence by psychiatric inpatients: a review. Hosp Commun Psychiatry 1991;42:585-590.

25. Niman HLI, Muris P, Merckelbaci HLGi et al. The Staff Observation Aggression Scale-Revised (SOAS-R). Aggr Behav 1999;25:197-209.

26. Palmstierna T, Nijman HLl, Wistedt B, Merckelbach HLGJ. Revision of the Staff Observation Aggression Scale (SOAS): comment on Hallsteinsen et al. Acta Psychiatt Scand 1999;100:80-81.

27. Gift AG. Visual Analogue Scales. Measurement of subjective phenomena. Nurs Res 1989;38:280-288.

28. Palmstierna T, Wistedt B. Staff observation aggression scale. Presentation and evaluation. Acta Psychiatr Scand 1987;76:657-663.

29. Steinert T, Wölfle M, Gebhardt RP. Measurement of violence during in-patient treatment and association with psychopathology. Acta Psychiatr Scand 2000;102:107-112.

30. Shah A. Chiu E, Ames D. The relationship between two scales measuring aggressive behavior among elderly nursing home residents. Int J Geriatr Psychiatry 1997;12:628-631.

31. ShaH A, DE T. The relationship between two scales measuring aggressive behavior among continuing-care psychogeriatric inpatients. Int Psychogeriatr 1997;9:471-477.

32. PATEL V, HOPE RA. A rating scale for aggressive behavior in the elderly. Psychol Med 1992;22:21 1-221.

33. Morrison EF. Violent psychiatric inpatients in a public hospital. Schol Inq Nurs Pract lnt J 1990;4:65-82.

34. Nijman HLi, a Campo JMLG, Ravelli DP, Mercki:LBACH HLGJ. A tentative model of aggression on inpatient psychiatric wards. Psychiatr Serv 1999;50:832-834. 